\title{
Inflammatory response, neutrophil activation, and free radical production after acute myocardial infarction: effect of thrombolytic treatment
}

\author{
D Bell, M Jackson, J J Nicoll, A Millar, J Dawes, A L Muir
}

\begin{abstract}
Activated neutrophils releasing proteolytic enzymes and oxygen free radicals have been implicated in extending myocardial injury after myocardial infarction. Neutrophil elastase was used as a marker of neutrophil activation and the non-peroxide diene conjugate of linoleic acid was used as an indicator of free radical activity in 32 patients after acute myocardial infarction; 17 were treated by intravenous thrombolysis. Patients with acute myocardial infarction had higher plasma concentrations of neutrophil elastase and the non-peroxide diene conjugated isomer of linoleic acid than normal volunteers or patients with stable ischaemic heart disease. Patients treated by thrombolysis had an early peak of neutrophil elastase at eight hours while those who had not been treated by thrombolysis showed a later peak 40 hours after infarction. The plasma concentration of non-peroxide conjugated diene of linoleic acid was highest 16 hours after the infarction irrespective of treatment by thrombolysis. Quantitative imaging with single photon emission tomography showed decreased uptake of indium-111 labelled neutrophils in the infarcted myocardium (as judged from technetium-99m pyrophosphate) in those who had received thrombolysis, suggesting a decreased inflammatory response.

The results indicate increased neutrophil activation and free radical production after myocardial infarction; they also suggest that thrombolysis does not amplify the inflammatory response and may indeed suppress it.
\end{abstract}

Activation of neutrophils with release of lysosomal enzymes and production of oxygen free radicals is an important part of the host defence mechanism against microbial infection. Activated neutrophils, however, have been implicated in the pathogenesis of several disease processes including emphysema, adult respiratory distress syndrome, and myocardial infarction. ${ }^{1}$ It has been suggested that the neutrophil may cause secondary heterolytic damage of myocytes, because neutrophil depletion limited infarct size in animal models of infarction ${ }^{2}$; the damage was attributed to the release of lysosomal enzymes ${ }^{4}$ or free radical production. ${ }^{5}$ Further experimental evidence suggests that reperfusion of ischaemic myocardium, for example after thrombolytic treatment, may be a double edged sword with the benefits of reoxygenation being partly offset by the potential harmful effects of reperfusion injury. ${ }^{6}$ Postulated mechanisms of reperfusion injury include plugging of small capillaries, ${ }^{7}$ generation of oxygen free radicals, ${ }^{8}$ calcium influx ${ }^{9}$ and neutrophil activation with release of lysosomal enzymes. ${ }^{10}$ Thus the neutrophil may have a role in reperfusion injury but its importance in patients has not been determined, though the clinical benefits of thrombolytic treatment are now established. ${ }^{11} 12$

Degranulation of neutrophils releases neutrophil elastase, a lysosomal enzyme; this has been used as a specific marker of neutrophil activation. ${ }^{13}$ Activated neutrophils are one potential source of oxygen free radical production. ${ }^{14}$ It is difficult to measure these unstable oxygen species but once they are generated they will react and oxidise adjacent molecules, particularly polyunsaturated fatty acids. ${ }^{15}$ The diene conjugated non-peroxide isomer of linoleic acid (phospholipid 9, 11-linoleic acid PL-9, 11-LA') has been used as a marker of human free radical activity. ${ }^{16}$ To determine if and when neutrophil activation takes place after myocardial infarction, we measured serial changes in plasma neutrophil elastase and PL9, 11-LA'. We also investigated how these indices were influenced by reperfusion by studying patients treated with and without thrombolytic agents. Finally, because the acute inflammatory infiltrate within myocardium after myocardial infarction can be imaged, ${ }^{17}$ we examined the effect of treatment with and without thrombolysis on the myocardial uptake of indium-111 labelled neutrophils.

\section{Patients and methods}

VALUES IN HEALTHY VOLUNTEERS AND PATIENTS WITH CHRONIC ISCHAEMIC HEART DISEASE

To establish a normal range for plasma concentrations of neutrophil elastase and the conjugated diene of linoleic acid, blood samples were taken from 35 healthy volunteers from laboratory and hospital staff. As a further control group we also studied 30 patients with a documented history of ischaemic heart disease based on coronary angiography $(n=12)$ or distant myocardial infarction $(\mathrm{n}=18)$ (table 1).

\section{PATIENTS WITH ACUTE MYOCARDIAL} INFARCTION

Observations were based on 32 patients who

\author{
Medicine, Royal Infirmary, \\ Edinburgh EH3 9YW. \\ Accepted for publicatic
19 September 1989 \\ National Blood
Transfusion S
Blood Compon
Assay Group,
Edinburgh \\ Correspondence to
}


Table 1 Characteristics of healthy volunteers, patients with chronic ischaemic heart disease, and patients with myocardial infarction

\begin{tabular}{|c|c|c|c|c|}
\hline & \multirow[b]{2}{*}{$\begin{array}{l}\text { Volunteers } \\
(n=35)\end{array}$} & \multirow[b]{2}{*}{$\begin{array}{l}I H D \\
(n=30)\end{array}$} & \multicolumn{2}{|c|}{ Myocardial infarction } \\
\hline & & & $\begin{array}{l}\text { No thrombolysis } \\
(n=15)\end{array}$ & $\begin{array}{l}\text { Thrombolysis } \\
(n=17)\end{array}$ \\
\hline Age (yr) & $\begin{array}{l}34 \\
(22-63)\end{array}$ & $\begin{array}{l}59 \\
(37-76)\end{array}$ & $\begin{array}{l}58 \\
(38-74)\end{array}$ & $\begin{array}{l}56 \\
(30-69)\end{array}$ \\
\hline $\mathrm{M} / \mathrm{F}$ & $30: 5$ & $24: 6$ & $10: 5$ & $13: 4$ \\
\hline WBC $\left(\times 10^{9} / 1\right)$ & $\begin{array}{l}5 \cdot 8 \\
(3 \cdot 4-9 \cdot 3)\end{array}$ & $\begin{array}{l}6 \cdot 7 \\
(5 \cdot 2-12 \cdot 6)\end{array}$ & $\begin{array}{l}13 \cdot 2 \\
(9 \cdot 6-23 \cdot 0)\end{array}$ & $\begin{array}{l}16 \cdot 8 \\
(7 \cdot 9-33 \cdot 7)\end{array}$ \\
\hline $\operatorname{LVEF}\left({ }^{0} 0\right)$ & - & 41 & & \\
\hline & & $(18-63)$ & $(15-71)$ & $(24-68)$ \\
\hline Peak creatıne kınase (U/I) & - & - & $\begin{array}{l}1635 \\
(522-6255)\end{array}$ & $\begin{array}{l}2059 \\
(533-6955)\end{array}$ \\
\hline Heparin (subcutaneously) & - & - & 15 & - \\
\hline Heparin (intravenously) & - & - & - & 17 \\
\hline Streptokinase/anistreplase & - & - & - & $9 / 8$ \\
\hline Lignocaine & - & - & 3 & 5 \\
\hline Hydrocortisone & - & - & - & 9 \\
\hline$\beta$ Blockers & - & 24 & 2 & 5 \\
\hline Diuretics & - & 4 & 6 & 5 \\
\hline Deaths & - & - & 2 & 1 \\
\hline
\end{tabular}

WBC, white blood cells; LVEF, left ventricular ejection fraction.

had sustained a recent acute anterior myocardial infarction. The diagnosis was based on the history of prolonged ischaemic chest pain, characteristic electrocardiographic changes, and increase in the enzyme creatine kinase. The patients were subdivided into the 17 who had been given intravenous thrombolysis with either 1200000 units streptokinase (Kabivitrum, Middlesex, UK), or 30 units of anistreplase (anisoylated plasminogen streptokinase complex (Eminase, Beecham Pharmaceuticals, Epsom, UK). The other 15 were deemed ineligible to receive thrombolytic treatment because of late admission ( $>4$ hours after the onset of symptoms), a history of active peptic ulceration, other source of haemorrhage, or recent cerebrovascular accident and were treated in conventional fashion. Table 1 shows the details of the two groups including drug treatment. All study times were taken from the onset of symptoms. All patients gave informed consent and the study was approved by the institute's ethics committee.

\section{PROTOCOL}

In patients with acute myocardial infarction blood was taken for full blood count and measurement of creatine kinase, neutrophil elastase, and linoleic acid (PL-9, 12-LA) and its diene conjugated non-peroxide isomer (PL-9, 11-LA') esterified as phospholipids. Samples were taken at $6-8$ hours after the onset of symptoms and every 8 hours thereafter until 48 hours. Samples were centrifuged and plasma separated immediately and held at $-20^{\circ} \mathrm{C}$ until analysis was performed.

PL-9, I I-LA' AND PL-9, I2-LA

The molar concentrations of PL-9, 11-LA' and PL-9, 12-LA in plasma were measured by high performance liquid chromatography in plasma after enzymatic hydrolysis with phospholipase $\mathrm{A}_{2}$ and solid phase sample preparation as described by Iversen et al. ${ }^{16}$ The intra-assay coefficient of variation was $<3.5 \%$. The results are expressed as $\mu \mathrm{mol} / 1$.

\section{PLASMA NEUTROPHIL ELASTASE}

Human neutrophil elastase was measured by specific radioimmunoassay with rabbit poly- clonal antiserum. ${ }^{13}$ The antigen was purified from human neutrophils after leucopheresis. The antibody was specific for neutrophil elastase and measured free enzyme and enzyme complexed to the natural inhibitors $\alpha_{1}$-proteinase inhibitor and $\alpha_{2}$-macroglobulin equally well. The results are expressed as $\mathrm{ng} / \mathrm{ml}$ and the intra-assay coefficient of variation was $<5 \%$.

\section{IMAGING}

Our previous work has shown that labelled neutrophil uptake within the myocardium can be imaged reliably providing the time from onset of infarction to reinjection of labelled cells is $<18$ hours. ${ }^{17}$ Only 21 of the patients could be studied by this technique within the appropriate time limits because of limited availability of the radionuclide indium-111. The patients received $20-30 \mathrm{MBq}$ of indium111 labelled autologous neutrophils within 18 hours of the onset of symptoms. Single photon emission tomography was undertaken 24 hours after the injection of the labelled cells with an IGE 400 AT maxicamera linked to a Siemens Microdelta computer. On the following day the patients were injected with $500 \mathrm{MBq}$ of (technetium-99m labelled pyrophosphate $\left({ }^{99} \mathrm{~m}\right.$ Tc-PYP) and two hours later further SPET imaging was undertaken to estimate infarct size. Apart from the different energy windows and imaging time the protocol on each day was identical. The single photon emission tomographic imaging was performed over $360^{\circ}, 64$ images being acquired and reconstruction being undertaken by back projection with a Butterworth filter to create sagittal, coronal, and transverse images. A study was regarded as positive when uptake could be clearly seen in all three views. In these studies all transverse slices for both indium-111 and ${ }^{99 \mathrm{~m}} \mathrm{Tc}-\mathrm{PYP}$ with uptake in the region of myocardium were then analysed by a semiautomatic programme that counted the number of volume cell elements (voxels) with values greater than $65 \%$ of the peak myocardial uptake. ${ }^{18}$ For each patient it was possible to compare the volume of myocardium showing neutrophil uptake with the volume of infarcted myocardium as judged from the pyrophosphate images.

Patients also had a predischarge radionuclide 
ventriculogram to assess residual left ventricular function.

STATISTICAL ANALYSIS

The Kolmogorov-Smirnov test showed that the data were not normally distributed. Results are therefore expressed as median and range. We used non-parametric analysis (Wilcoxon rank sum test) for two independent samples (Mann-Whitney). Values of $p<0.05$ were taken as significant and data were analysed by computer with the statistical package for social sciences (SPSS Inc, Chicago).

\section{Results}

WHITE BLOOD CELL COUNT

The white blood cell count was significantly lower in the normal volunteers $\left(5.8 \times 10^{9} / 1\right.$ $3 \cdot 4-9 \cdot 3 / 1$ ) than in patients with ischaemic heart disease without recent infarction $\left(6.7 \times 10^{9} / 1\right.$ $5 \cdot 2-12.6 / 1, p<0.004)$ and in both groups counts were lower than the initial white cell count in patients with acute myocardial infarction $\left(16.4 \times 10^{9} / 1,7.9-33.7, \mathrm{p}<0.0001\right)$. This was also true for the neutrophil count for the three groups.

\section{PLASMA NEUTROPHIL ELASTASE}

The plasma concentration of neutrophil elastase was significantly lower in the normal volunteers $(18.6 \mathrm{ng} / \mathrm{ml}, 9.2-51.0)$ than in the patients with stable ischaemic heart disease $(25.8 \mathrm{ng} / \mathrm{ml}, 12 \cdot 2-49.5, \mathrm{p}<0.002)$. For the 48 hours after myocardial infarction, however, plasma neutrophil elastase was higher than in either normal volunteers or patients with ischaemic heart disease (fig 1a). The time course differed in patients who had received thrombolytic treatment and in those who had not.

PL-9, II-LA' AND THE MOLAR RATIO PL-9, I I-LA'/PL-9, I2-LA

There was no significant difference in PL-9, 11-LA ${ }^{\prime}$ or the molar ratio PL-9, 11-LA' PL-9, 12-LA between normal volunteers $(19 \cdot 3$ $\mu \mathrm{mol} / 1,7 \cdot 5-32 \cdot 9 ; 4 \cdot 7,1 \cdot 9-9 \cdot 1)$ and patients with ischaemic heart disease $(19.8 \mu \mathrm{mol} / 1,7.9$ $43 \cdot 2 ; 5 \cdot 4,1 \cdot 7-12 \cdot 1)$. For the 48 hours after myocardial infarction PL-9, 11-LA' was significantly greater than in the healthy volunteers. The concentration reached a maximum at 16 hours; by 48 hours the values were not significantly greater than those of patients with chronic ischaemic heart disease (fig 1b). The molar ratio of PL-9, 11-LA'/PL-9, 12-LA was significantly increased in the 48 hours after myocardial infarction and followed a similar time course.

COMPARISON OF PATIENTS WITH MYOCARDIAL INFARCTION WHO WERE TREATED BY THROMBOLYSIS AND THOSE WHO WERE NOT There was no significant difference in peak creatine kinase activity between patients treated conventionally and those who were treated by thrombolysis. Plasma activity of creatine kinase reached a peak earlier in those treated by thrombolysis (16 hours) than in
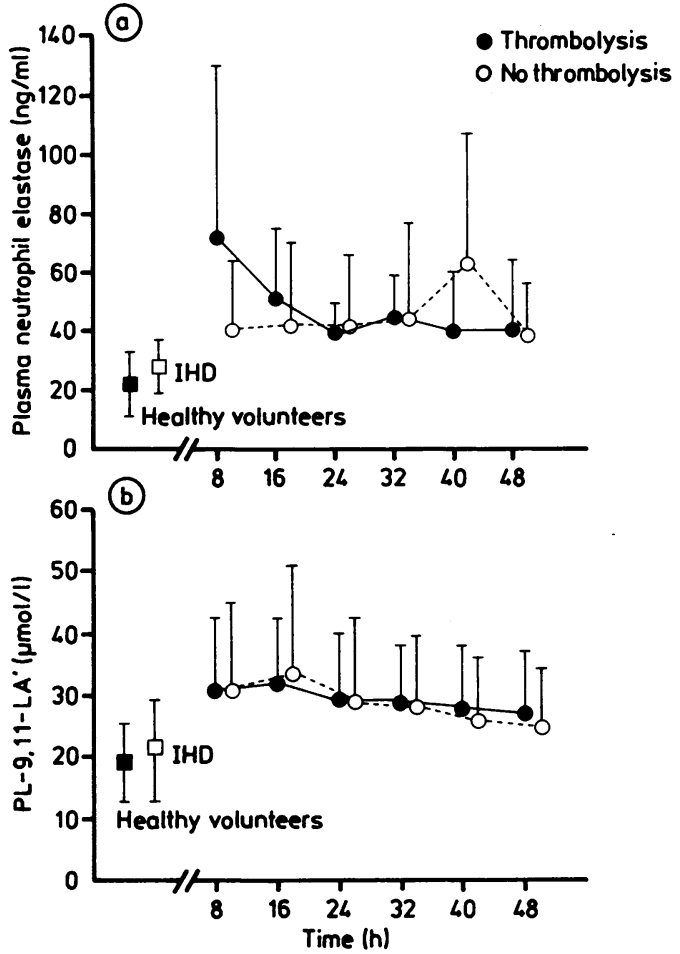

Figure 1 (a) Mean plasma neutrophil elastase (1 SD) in healthy volunteers, patients with chronic ischaemic heart disease (IHD), and those with acute myocardial infarction. Changes in plasma concentration neutrophil elastase (PNE) after myocardial infarction are shown for those treated with and without thrombolysis. The values of PNE are significantly greater at all sampling times after myocardial infarction than in healthy volunteers or patients with chronic ischaemic heart disease. Patients treated by thrombolysis have significantly higher values of PNE at 8 hours $(p<0.025)$ and lower values at 40 hours $(p<0.037$ than those not treated by thrombolysis. (b) Mean PL-9, 11-LA' (1SD) in the same groups showing significantly higher values after myocardial infarction than in

ischaemic heart disease or in healthy volunteers. There was no difference between those treated by thrombolysis and those not treated by thrombolysis at any time.

those treated conventionally (24 hours). Similarly, there was no significant difference in the left ventricular ejection fraction measured by radionuclide ventriculography, 10 days after infarction, though those patients who were treated by thrombolysis had slightly higher values (table 1 ).

\section{PLASMA CONCENTRATIONS OF NEUTROPHIL} ELASTASE

The pattern of change in plasma neutrophil elastase differed in the two groups of patients with acute myocardial infarction (fig 1a). Patients given intravenous thrombolysis had higher early maximal values at 8 hours $(48 \cdot 2 \mathrm{ng} /$ $\mathrm{ml}, 25-250)$ than those treated conventionally $(32.6 \mathrm{ng} / \mathrm{ml}, 15 \cdot 6-101, \mathrm{p}<0.025)$. Those treated conventionally tended to have lower early values with a late peak at 40 hours $(49.8$ $\mathrm{ng} / \mathrm{ml}, 21 \cdot 4-196)$ than those treated with thrombolysis $(34.2 \mathrm{ng} / \mathrm{ml}, 15 \cdot 8-83, \mathrm{p}<0.037)$.

PL-9, I I-LA' AND THE MOLAR RATIO PL-9, I ILA'/PL-9, I2-LA

There was no significant difference in PL-9, 11-LA' ${ }^{\prime}$ or the molar ratio PL-9, 11-LA'/PL-9, 12-LA in those treated conventionally after 
Table 2 Details of patients treated with and without thrombolysis who were imaged with "'In labelled neutrophils and ${ }^{99 m} T c$ pyrophosphate

\begin{tabular}{|c|c|c|c|c|c|c|}
\hline & $\begin{array}{l}C K \max \\
(U / l)\end{array}$ & $\begin{array}{l}\text { LVEF } \\
(\%)\end{array}$ & $\begin{array}{l}\text { Time to injection } \\
\text { (h) }\end{array}$ & $\begin{array}{l}{ }^{\prime \prime \prime} \text { In } \\
\text { (voxels) }\end{array}$ & $\begin{array}{l}{ }^{99 m} T c \\
\text { (voxels) }\end{array}$ & $\left.{ }^{\prime \prime \prime} \operatorname{In}\right|^{99 m} T_{c}$ \\
\hline $\begin{array}{l}\text { No thrombolysis } \\
(n=10) \\
\text { Thromolysis } \\
(n=11) \\
p\end{array}$ & $\begin{array}{l}2508 \\
(522-6255) \\
2500 \\
(533-6955) \\
\text { NS }\end{array}$ & $\begin{array}{l}36 \\
(15-51) \\
40 \\
(27-68) \\
\text { NS }\end{array}$ & $\begin{array}{l}8 \\
6 \cdot 5-10 \\
11 \\
5-18 \\
\text { NS }\end{array}$ & $\begin{array}{l}114 \\
(19-276) \\
81 \\
(0-160) \\
\text { NS }\end{array}$ & $\begin{array}{l}201 \\
(77-405) \\
217 \\
(111-323) \\
\text { NS }\end{array}$ & $\begin{array}{l}0 \cdot 79 \\
(0 \cdot 06-2 \cdot 14) \\
0 \cdot 41 \\
(0-0.96) \\
<0.05\end{array}$ \\
\hline
\end{tabular}

(Each voxel or volume picture cell element represents approximately $250 \mathrm{~mm}^{3}$.)

CK, creatine kinase; LVEF, left ventricular ejection fraction.

myocardial infarction and those given thrombolysis. For both groups the values were greatest at 16 hours, gradually falling towards normal values (fig $1 \mathrm{~b}$ ).

There was no correlation between the white blood cell count and plasma concentration of neutrophil elastase in any of the groups. There was a weak correlation between white cell count and PL-9, 11-LA' in the non-thrombolytic group $(r=0.63, p<0.02)$, and in patients with ischaemic heart disease $(r=0.45, p<0.02)$, but this did not hold for the corrected molar ratio and no correlations were found in the normal volunteers and patients treated with thrombolysis.

\section{IMAGING (TABLE 2)}

In general, in the patients who were imaged there was a significantly greater number of voxels showing an uptake of ${ }^{99 \mathrm{~m}} \mathrm{Tc}$ pyrophosphate than of ${ }^{111}$ In labelled neutrophils ( $p<0.0006)$. Uptake of ${ }^{99 \mathrm{~m}} \mathrm{Tc}$ pyrophosphate was very similar in patients who were treated by thrombolysis and those who were not, suggesting little difference in infarct size in these patients. This is supported by similar values of residual left ventricular ejection fraction and peak creatinine kinase in both groups (table 2). In contrast, the uptake of ${ }^{111}$ In labelled neutrophils was less in the patients who were treated by thrombolysis. Thus the ratio of ${ }^{111} \mathrm{In} /{ }^{99 \mathrm{~m}} \mathrm{Tc}$, which serves as an estimate of the inflammatory response for a given infarct size, was significantly less in patients treated by thrombolysis $(0.41$, range $0-0.96)$ than in those treated without $(0.79$, range $0.06-2 \cdot 14, \mathrm{p}<$ 0.05 ). In fig 2 an example of the greater uptake of ${ }^{111}$ In labelled neutrophils in a patient treated without thrombolysis is contrasted with that

Figure 2 Single photon emission tomographic images comparing the uptake of "In labelled neutrophils with the size of infarction as assessed by ${ }^{99 m}$ Tc-pyrophosphate (PYP). The upper pair of images show easily detected uptake of "In and ${ }^{99 m} T c$ $P Y P$ in a patient with anterior myocardial infarction who was not given thrombolytic treatment. The lower pair of images show markedly reduced uptake of " In labelled neutrophils compared with ${ }^{99 m}$ Tc-PYP in a patient with anterior myocardial infarction treated with anistreplase.

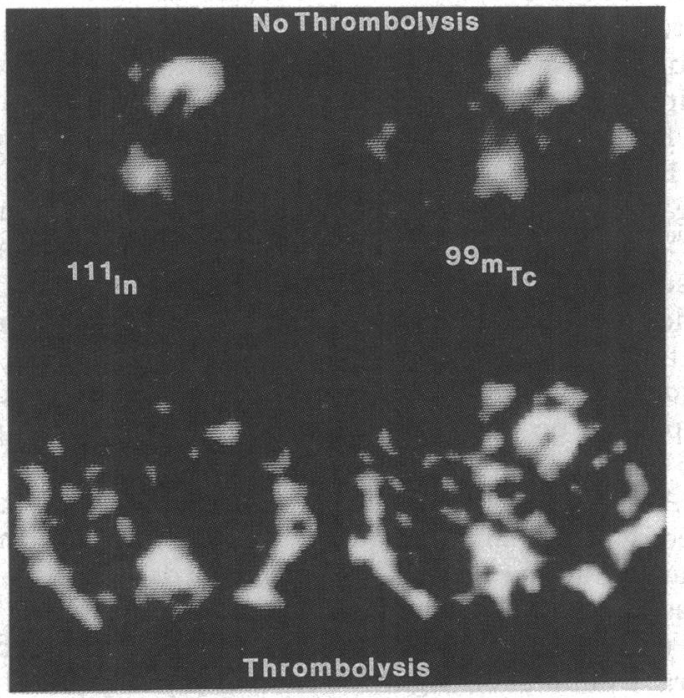

seen in a patient who had received streptokinase.

\section{Discussion}

We found both an increased neutrophil elastase release and an increase in the plasma concentrations of the diene conjugated non-peroxide isomer of linoleic acid (PL-9, 11-LA') after myocardial infarction. The association of leucocytosis and the severity of myocardial infarction was first described by White in 1926. ${ }^{19}$ We noted increased neutrophil leucocytosis after myocardial infarction but there was no correlation between the peripheral neutrophil count and the raised plasma concentrations of neutrophil elastase. A distinction must be made between whole blood elastase and plasma elastase. Whole blood elastase correlates with the total neutrophil count but is not a marker of neutrophil activation and reflects the much greater intracellular stores of the enzyme. Increased plasma neutrophil elastase relates to neutrophil degranulation and presumably reflects release within the area of myocardial injury. The peripheral leucocytosis is part of the more general response to stress. ${ }^{20}$ Like others we also noted an increased leucocyte count in patients with stable ischaemic heart disease and this has been shown to be a predictor of future myocardial events. ${ }^{21}$ The neutrophil has been recognised as an early part of the inflammatory response to myocardial infarction, ${ }^{22}{ }^{23}$ but it is only more recently that experimental evidence has been put forward to suggest that it may be involved in secondary heterolytic myocyte damage after myocardial infarction ${ }^{45}$ and that suppression of the neutrophil infiltrate can reduce infarct size. $^{23}$ One mechanism by which activated neutrophils can induce cell damage is through the release of potent proteolytic enzymes.

Neutrophil elastase is a serine protease released from the primary granules after major cell stimulation such as phagocytosis or cell death. ${ }^{24}$ It has a wide range of substances including elastin, collagen, fibrinogen, and other matrix macromolecules and is implicated in the pathogenesis of several human diseases. ${ }^{1}$ Our study showed that plasma concentrations of human neutrophil elastase were significantly higher in patients after myocardial infarction than in healthy volunteers and patients with stable ischaemic heart disease. Further, the pattern of elastase release was different in patients treated conventionally and in those treated with thrombolysis. In patients treated with streptokinase or anistreplase there was a significant early increase in plasma neutrophil 
elastase within the first few hours of treatment. This confirms previous observations ${ }^{25}$ and it seems likely that this represents clot lysis or intracoronary activation of neutrophils because few inflammatory cells will have migrated into myocardial tissue by this stage. ${ }^{22} 23$

In contrast, in patients treated conventionally concentrations of neutrophil elastase reach a peak later, between 32 and $\mathbf{4 0}$ hours after the onset of symptoms, when the inflammatory infiltrate is present histologically and can be imaged. ${ }^{17}$ Drug treatment, particularly hydrocortisone or lignocaine, might be expected to influence neutrophil behaviour. But a similar number of patients in both groups received lignocaine, which is known to depress neutrophil function in vitro. ${ }^{26}$ Also patients given hydrocortisone before streptokinase did not have lower ${ }^{111}$ In uptake by neutrophils or lower concentrations of elastase than patients treated with anistreplase, who did not receive hydrocortisone. This suggests that the results in the thrombolytic group are not influenced by the potential suppressive effect of hydrocortisone on the inflammatory response and neutrophil function. ${ }^{27}$

Although the neutrophil is a source of cytotoxic oxygen species, there are other potential sources of oxygen free radical production after myocardial infarction, including the conversion of xanthine dehydrogenase to xanthine oxidase, mitochondrial production, the auto-oxidation of catecholamines, and the arachidonic acid cascade. ${ }^{8}$ Although xanthine dehydrogenase is converted to xanthine oxidase in the vascular endothelium, this enzyme system is not present in human myocytes and is therefore unlikely to be directly involved in myocardial damage. ${ }^{28}$ Therefore, the most likely sources of free radical production within the human myocardium are the electron transport chains of the myocyte mitochondria or from activated neutrophils via the membrane linked nicotinamide adenine dinucleotide phosphate (reduced form) (NADPH) oxidase. ${ }^{10}$ Our studies of peripheral blood did not define the increase as being of myocardial origin, but the myocardium is the most likely site in patients who are haemodynamically stable.

Products of lipid peroxidation have been used as markers of free radical activity because exposure of cell membranes to oxygen free radicals stimulates "lipid peroxidation"29perhaps better termed lipid oxidation. Lipid peroxidation products have themselves been implicated in damaging cell membranes after myocardial infarction, ${ }^{30}$ though some have suggested that increased evidence of lipid peroxidation merely reflects cell damage. ${ }^{15}$ For this reason we chose to measure the diene conjugated non-peroxide isomer of linoleic acid PL-9, 11-LA' in plasma because this is thought to be a marker of human free radical activity. ${ }^{1631}$ PL-9, 11-LA' is present in the diet and can be manufactured by bacterial flora and this may account for the conflicting reports of the usefulness of this as a marker of cervical cancer. ${ }^{32}{ }^{33}$ It is unlikely that changes in dietary intake or bacterial flora would alter signifi- cantly in the 48 hours after myocardial infarction to account for the changes seen in plasma PL-9, 11-LA'. Also the concentrations were not increased in the patients with stable, but documented ischaemic heart disease and there was no change in linoleic acid, which is also affected by dietary intake.

Heparin was shown to increase $9,11-\mathrm{LA}^{\prime 34}$ the assay method, which is designed to measure the molar concentration of 9,11-LA' and 9,12LA esterified as phospholipids, also measures 9,11-LA' and 9,12-LA present as free fatty acids. Free fatty acids are increased by the lipolytic action of heparin though the magnitude of the response is often overestimated because the method does not take account of the extensive ex-vivo lipolysis. ${ }^{35}$ In our study heparin is unlikely to have had any significant effect because the thrombolytic group received only intravenous heparin as an adjuvant to thrombolysis a mean of 18 hours 36 minutes after the onset of symptoms. The patients treated conventionally also received heparin but as a low dose subcutaneously. We noted no difference in the values of PL-9, 11-LA between the two groups despite the widely different heparin regimens. The similarity of responses of the two groups also argues for a lack of effect of the thrombolytic drugs in themselves on PL-9, 11-LA'

The concentration of PL-9, 11-LA' or the molar ratio did not correlate with creatine kinase measured on the same sample and it therefore seems unlikely that the raised concentrations are merely a marker of cell damage $^{15}$ and the evidence is consistent with the diene being a free radical marker in human beings. In general, in patients with myocardial infarction the values of PL-9, 11-LA' and the molar ratio were high initially and then fell; this suggests that maximum free radical generation occurs early. We were unable to detect any difference in the concentrations of PL-9, 11$\mathrm{LA}^{\prime}$ or the molar ratio of $\mathrm{PL}-9,11-\mathrm{LA}^{\prime} / \mathrm{PL}-9$, 12-LA between patients treated conventionally and those who received thrombolysis. This lack of difference in the molar ratio (indeed it was somewhat lower in the group treated by thrombolysis) suggests that reperfusion was not associated with a delayed or secondary increase in free radical production with the potential for further myocardial damage. Even when samples were taken earlier (less than 6 hours after the onset of symptoms) we did not detect any difference in those treated by thrombolysis. We cannot exclude the immediate increase in free radical production after reperfusion shown in some animal studies. ${ }^{36}$ However, in human beings free radical injury after reperfusion may be reduced by the presence of red blood cells, which contain the antioxidant enzyme catalase ${ }^{37}$ unlike the cell free perfusate often used in animal experiments.

This study confirms that the human inflammatory response to myocardial infarction can be imaged. In only two of the 21 patients studied no uptake of ${ }^{111}$ In-labelled neutrophils could be detected. Both patients had been treated by thrombolysis and although this 
result could represent failed imaging, this is unlikely because all the thrombolytic group had significantly reduced uptake of neutrophils in relation to infarct size assessed by ${ }^{99 \mathrm{~m}} \mathrm{Tc}$ pyrophosphate. The concept of a reduced inflammatory response is supported by the different patterns of release of neutrophil elastase. If the early neutrophil activation in those given thrombolysis represents intracoronary activation and the late response corresponds to acute inflammatory infiltrate within damaged myocardium we would expect greater neutrophil uptake in those who did not receive thrombolytic agents. As an extension, the lack of a late increase in lipid oxidation suggests that the neutrophil is not the main source of free radical production in myocardial infarction. By inference this implies that if there is later heterolytic myocardial injury and if it is mediated by neutrophils, it may be secondary to release of proteolytic enzymes rather than oxygen free radicals. The results do not necessarily contradict the experimental evidence that suggests that free radical scavengers reduce myocardial damage, ${ }^{36}$ because there is evidence that superoxide dismutase may work in part by reducing neutrophil migration. ${ }^{38} \mathrm{It}$ is therefore possible that some of the beneficial effects of thrombolysis are the result of partial inhibition of the inflammatory response to myocardial injury, perhaps by reducing the degree or duration of production of neutrophil chemoattractants, such as complement. $^{39} 40$

Our studies suggest that after acute myocardial infarction neutrophils are activated and free radicals are produced. Although animal studies suggest such activation can extend myocardial injury we have no evidence of this in human beings. However, thrombolysis and presumed reperfusion are not associated with amplification of the inflammatory response or prolonged free radical production in patients. Indeed these responses seem to be diminished and some of the beneficial effects of thrombolysis may be the result of down regulation of the acute inflammatory response.

We thank Dr R Elton for his advice on the analysis of these data The internal standard for the high performance liquid chromatography assay was kindly supplied by Dr D G Wickens, and the antigen for the radioimmunoassay was supplied by Dr P Davis. This work was in part supported by grants from the British Heart Foundation and the Scottish Home and Health Department.

1 Malech HL, Gallin JI. Neutrophils in human diseases. N Engl J Med 1987;317:687-94

2 Romson JL, Hook BG, Kunkel SL, Abrams GD, Shork MA, Lucchesi BR. Reduction of the extent of ischemic myocardial injury by neutrophil depletion in the dog. Circulation 1983;67:1016-23.

3 Jolly SR, Kane WJ, Hook BG, Abrams GD, Kunkel SL, Lucchesi BR. Reduction of myocardial infarct size by neutrophil depletion: effect of duration of occlusion. Am Heart $J$ 1986;112:682-90.

4 Engler RE. Granulocytes and oxidative injury in myocardial ischemia and reperfusion. Fed Proc 1987;46:2395-6.

$5 \mathrm{McCord} \mathrm{JM}$. Oxygen-derived free radicals in post-ischemic tissue injury. N Engl J Med 1985;312:159-63.

6 Braunwald E, Kloner RA. Myocardial reperfusion. A double edged sword. J Clin Invest 1985;76:1713-9.

7 Kloner RA, Ganote CE, Jennings RB. The "no-reflow" phenomenon after temporary coronary occlusion in the phenomenon after temporary corona

8 Werns SW, Shea MJ, Lucchesi BR. Free radicals and myocardial injury: pharmacologic implications. Circulation 1986;74:1-5.

9 Hearse DJ. Reperfusion of the ischaemic myocardium. J Mol Cell Cardiol 1977;9:605-15.

10 McCord JM. Oxygen-derived radicals: a link between reperfusion injury and inflammation. Fed Proc 1987; 46:2402-6.

11 Gruppo Italiano per lo Studio della Streptochinasi nell' infarto (GISSI). Effectiveness of intravenous thrombolytic treatment in acute myocardial infarction. Lancet 1986;i:397-401.

12 ISIS-2 (Second International Study of Infarct Survival). Randomised trial of intravenous streptokinase, oral aspirin, both, or neither among 17187 cases of suspected acute myocardial infarction. Lancet 1988;ii:349-60.

13 Plow EF. Leucocyte elastase release during blood coagulation. A potential mechanism for activation of the alternative fibrinolytic pathway. J Clin Invest 1982;69:564-72.

14 Babior BM. Oxygen-dependent microbial killing by phagocytes. N Engl J Med 1978;298:659-68.

15 Halliwell B, Gutteridge JMC. Lipid peroxidation, oxygen radicals and anti-oxidant therapy. Lancet 1984;i:1396-7.

16 Iversen SA, Cawood P, Dormandy TL. A method for the measurement of a diene-conjugated derivative of linoleic acid, 18:2 9,11$)$ in serum phospholipid, and possible origins. Ann Clin Biochem 1985;22:137-40.

17 Bell D, Jackson M, Millar AM, Nicoll JJ, Connell M, Muir $A L$. The acute inflammatory response to myocardial infarction: imaging with indium-111 labelled autologous infarction: imaging with indium-111

18 Jansen DE, Corbett JR, Wolfe CL, et al. Quantification of myocardial infarction: a comparison of single photon emission computed tomography with pyrophosphate to serial plasma MB-creatine kinase measurements. Circulation 1985;72:327-33.

19 White PD. The prognosis of angina pectoris and of coronary thrombosis. JAMA 1926;87:1525-30.

20 Bierman JA, Kelly KH, Cordes FL, Byron RL, Polhemus JA, Rappaport $S$. The release of leukocytes and platelets from the pulmonary circulation by epinephrine. Blood 1952;7:683-92.

21 Ernst E, Hammerschmidt E, Bagge E, Matrai A, Dormandy JA. Leuckocytes and the risk of ischemic diseases. JAMA 1987;257:2318-24.

22 Mallory GK, White PD, Salcedo-Salger J. The speed of healing of myocardial infarction. Am Heart $J$ 1939; 18:647-71.

23 Sommers HM, Jennings RB. Experimental acute myocardial infarction. Lab Invest 1964;12:1491-503.

24 Gallin JI. Neutrophil specific granules: a fuse that ignites the inflammatory response. Clin Res 1984;32:320-8.

25 Gutteridge CN, Burrell C, Newland AC. Neutrophil CR3 expression and leucocyte elastase release during thrombolysis with APSAC. Br J Haematol 1988;69:116. 26 Goldstein IM, Lind S, Hoffstein S, Weissman G. Influence of local anaesthetics upon human polymorphonuclear leucocyte function in vitro. $J \operatorname{Exp} M$ Med 1977;146:483-94.

27 Hart DHL. Polymorphonuclear leucocyte elastase activity is increased by bacterial lipopolysaccharide: a response inhibited by glucocorticoids. Blood 1984;63:421-6.

28 Manfredi JP, Holmes EW. Purine salvage pathways in myocardium. Annu Rev Physiol 1985;47:691-705.

29 McBrien DCH, Slater TF, eds. Free radicals, lipid peroxidation, and cancer. London: Academic Press, 1982.

30 Meerson FZ, Kagan VE, Kozlov YP, Belkina LM, Arkhipenko YV. The role of lipid peroxidation in pathogenesis of ischaemic damage and the antioxidant

31 Fink R, Marjot DH, Cawood P, et al. Increased free radical activity in alcoholics. Lancet 1985;ii:291-4.

32 Singer A, Tay SK, Griffin JFA, Wickens DG, Dormandy TL. Diagnosis of cervical neoplasia by the estimation of TL. Diagnosis of cervical neoplasia by the estim

33 Green AJE, Starkey BJ, Halloran SP, et al. Diagnostic significance of octadeca-9,11-dienoic acid in cervical neosignificance of octadeca-9,11-
plasia. Lancet 1988;ii:309-11.

34 Wickens DG, Griffin JF, Maher ER, Curtis JR, Dormandy TL. The effect of systemic heparinisation and haemodialysis on plasma octadeca-9-11-dienoic acid (9,11-LA'). Free Radic Res Commun 1987;3:99-106.

35 Riemersma RA, Logan R, Russell DC, Smith HJ, Simpson $\mathrm{J}$, Oliver MF. Effect of heparin on plasma free fatty acid concentrations after acute myocardial infarction. Br Heart $J 1982 ; 48: 134-9$.

36 Schlafer M, Kane PF, Wiggins VY, Kirsh MM. Possible role for cytotoxic oxygen metabolites in the pathogenesis of cardiac ischemic injury. Circulation 1982 66(suppl I):85-92.

37 Agar NS, Sadrzadeh SMH, Hallaway PE, Eaton JW. Erythrocyte catalase: a somatic oxidant defense. J Clin Invest 1986;77:319-21.

38 McCord JM, Wonk K, Stokes SH, Petrone WF, English DK. A mechanism for the anti-inflammatory activity of DK. A mechanism for the anti-inflammatory activity of
superoxide dismutase. In: Autor AP, ed. Pathology of superoxide dismutase. In: Autor AP, ed. Patholo
oxygen. New York: Academic Press, 1982:75-83.

oxygen. New York: Academic Press, 1982:75-83.
39 Hill JH, Ward PA. The phlogistic role of $\mathrm{C} 3$ leukotactic fragments in myocardial infarcts of rats. J Exp Med fragments in myocar

40 Hartmann JR, Robinson JA, Gunnar RM. Chemotactic activity in the coronary sinus after experimental myocardial infarction. Effects of pharmacologic interven of ischemic injury. Am J Cardiol 1977;40:550-5. 